\title{
Metformin-associated lactic acidosis (MALA) in a peritoneal dialysis patient
}

\author{
Nam Ho Kim \\ Department of Internal Medicine, Chonnam National University Medical School, Gwangju, Korea
}

Received April 22, 2021

Revised May 26, 2021

Accepted June 2, 2021

Corresponding author

Nam Ho Kim

Department of Internal Medicine,

Chonnam National University

Medical School, Baekseo-ro,

Dong-gu, Gwangju 61469, Korea

Tel: +82-62-220-6270

Fax: +82-62-225-8578

E-mail: nhk111@jnu.ac.kr

ORCID:

https://orcid.org/0000-0002-0898-5428

\begin{abstract}
Metformin-associated lactic acidosis (MALA) is a rare but sometimes fatal complication. I report a case of MALA in a man aged 59 years treated with continuous ambulatory peritoneal dialysis and was taking metformin about a month ago. He was brought to the hospital for dyspnea and diarrhea. Laboratory finding showed high anion gap metabolic acidosis with elevated lactate level. He received continuous renal replacement therapy due to severe acidosis and hemodynamic instability occurred during admission. His $\mathrm{pH}$ and lactate level was normalized within 48 hours. Though obvious correlation between metformin and lactic acidosis in end-stage renal disease was not found, caution is needed to use metformin in these patients.
\end{abstract}

Keywords: Metformin; Lactic acidosis; Peritoneal dialysis; CRRT

\section{INTRODUCTION}

Metformin is a very commonly used oral anti-hyperglycemic agent in the biguanide class, which was discovered in 1922 [1]. Metformin considered as first-line medication for the treatment of type 2 diabetes [2]. However, metformin has limited use in advanced chronic kidney disease (CKD) patients. Because it increases the risk of the lactic acidosis which is the most serious potential adverse effect of metformin, especially in patients with decreased glomerular filtration rate (GFR). Metformin-associated lactic acidosis (MALA) is very rare condition, but it can be fatal in some case. Here, we present a case of fatal metformin-associated lactic acidosis, occurred in a patient with peritoneal dialysis. This study was approved by the Institutional Review Board
(IRB) of Chonnam National University Hospital (IRB number: CNUH-EXP-2021-125). The IRB waived the need for written consent from the patients, because this study had a retrospective design.

\section{CASE REPORT}

A 59-year-old man on continuous ambulatory peritoneal dialysis (CAPD) with end-stage renal disease (ESRD) was admitted to the emergency department at Chonnam National University Hospital, complaining of dyspnea and diarrhea that persisted over 1 day. He had a history of hypertension, type 2 diabetes mellitus (for which he received medication) for over 10 years. He started peritoneal dialysis due to ESRD at about three years ago and had been maintained on 
CAPD. He had experienced left anterior descending artery territory myocardial infarction seven months before and received percutaneous coronary intervention (PCI). After two months and six months of PCI, he had recurrent episode of in-stent restenosis (ISR). Because he had additional critical stenosis of right coronary artery with heavily calcification and moderate stenosis of left circumflex artery, he received coronary artery bypass graft (CABG) surgery one month before admission. He received metformin 500mg twice a day from 3 days after CABG and discharged with same medication. One month after discharged from hospital, he admitted to emergency room.

His blood pressure was 100/60 $\mathrm{mmHg}$, heart rate was 80 beat per min, respiratory rate was 20 per min, and body temperature was $36.5^{\circ} \mathrm{C}$. At the initial laboratory tests, white blood cell (WBC) count was 11,000 cells $/ \mathrm{mm}^{3}$ (absolute neutrophil count, $9,740 / \mathrm{mm}^{3}$ ). C-reactive protein level, a blood urea nitrogen level and a creatinine level were $0.6 \mathrm{mg} / \mathrm{dL}, 76.2 \mathrm{mg} / \mathrm{dL}$, and $15.0 \mathrm{mg} / \mathrm{dL}$, respectively. On arterial blood gas analysis, $\mathrm{pH} 7.12, \mathrm{pCO}_{2} 18 \mathrm{mmHg}, \mathrm{pO}_{2}$ $224 \mathrm{mmHg}, \mathrm{HCO}_{3}{ }^{-} 5.3 \mathrm{mmol} / \mathrm{L}$ was checked. His sodium, chloride and potassium were $129 \mathrm{mEq} / \mathrm{L}, 92 \mathrm{mEq} / \mathrm{L}$ and 4.2 $\mathrm{mEq} / \mathrm{L}$ respectively, so high anion gap metabolic acidosis (anion gap=31.7) was detected. Plasma lactate level at initial blood sample was markedly elevated to $17.7 \mathrm{mmol} / \mathrm{L}$ and there was no evidence of hypoperfusion (like hypovolemia, cardiac failure, sepsis), diabetic ketoacidosis or other drug intoxication, so he was diagnosed as severe lactic acidosis.

He admitted to intensive care unit (ICU) due to severe metabolic acidosis, and he had performed continuous renal replacement therapy (CRRT) by continuous veno-venous hemodiafiltration (CVVHDF) mode, because his blood pressure was descended to 70/40 $\mathrm{mmHg}$ after admission. After 48 hours of CRRT treatment, serum bicarbonate level was recovered to near normal range $(22-26 \mathrm{mmol} / \mathrm{L})$. Lactic acid level also normalized. At third day of hospitalization, he transferred to general ward and restarted CAPD. With conservative treatment, his general condition was recovered, and he discharged at $22^{\text {nd }}$ day of hospitalization uneventfully.

\section{DISCUSSION}

MALA is known to be rare, with reported incidence of 5-9 per 100,000 person years [3,4], which is not more than the general population. Despite it is a rare disease, MALA remains a big concern because of the high mortality rate. Almost all cases of MALA occurred in patients with predisposing conditions like renal impairment, heart failure, hepatic failure, pulmonary decompensation, sepsis and dehydration. The most recent meta-analysis concluded that there is no evidence that metformin treatment increases the incidence of lactic acidosis compared with other anti-hyperglycemic agents [5]. But current guidelines [6] still recommend that metformin should be discontinued when estimated GFR is $<30 \mathrm{~mL} / \mathrm{min} / 1.73 \mathrm{~m}^{2}$, and metformin use should be reevaluated at an estimated GFR $<45 \mathrm{~mL} / \mathrm{min} / 1.73 \mathrm{~m}^{2}$ with a reduction in maximum dose to $1,000 \mathrm{mg} /$ day [7].

Metformin, known as hepatic and muscle 5'-adenosine monophosphate-activated protein kinase (AMPK) activator [8], primarily act by reducing hepatic gluconeogenesis and increasing muscular glucose uptake [9]. Although, metformin is a relatively safe anti-hyperglycemic agent, lactic acidosis might be life threatening, with mortality rate about $50 \%$. The mechanism of MALA is that the metformin increases plasma lactate levels relates to the inhibition of mitochondrial respiration in liver and muscle tissues responsible for lactate removal, and this might result in both accelerated lactate production and reduced lactate metabolism [10,11]. Significant lactic acidosis occurs only in the presence of comorbid conditions including renal failure, hepatic failure, heart failure, hypoxic state, dehydration or hemodynamic instability. In our patient, volume depletion due to diarrhea might be a predisposing factor.

It is not clear whether peritoneal dialysis might aggravate the lactic acidosis. Currently used peritoneal dialysate solution contains lactic acid in part. Lactic acid would be absorbed during peritoneal dialysis and it could worsen lactic acidosis. However, Dixon et al. [12] showed that peritoneal dialysis with lactate containing solution itself do not develop lactic acidosis. Rather, some authors used peritoneal dialysis as a treatment of lactic acidosis [13-15].

By the current guidelines, metformin is contraindicated in end-stage renal disease. So, MALA in patients on peritoneal dialysis is very rare and, to our best knowledge, there were only 4 case reports of MALA in peritoneal dialysis patients. The first reported patient, 59-year-old man on CAPD and treated with metformin for more than three years, survived 
by managed with bicarbonate-based hemodialysis [16]. The second patient, 76-year-old woman on CAPD, treated using peritoneal dialysis with bicarbonate buffered solution, but she did not survive [17]. Another 62-year-old woman, who was accidentally prescribed metformin, was successfully treated with hemodialysis [18]. The most recent case, 83-year-old man on peritoneal dialysis, managed with conventional hemodialysis without noted complication [19]. Our patient, the fifth case of MALA in peritoneal dialysis patient, was treated successfully with CRRT. In fact, CRRT is known to be less effective for metformin elimination than conventional hemodialysis [20]. We had no choice but to do the CRRT, because his blood pressure was fall to $70 / 40 \mathrm{mmHg}$ just after ICU admission.

In summary, we have reported a case of metformin-associated lactic acidosis which successfully treated with continuous renal replacement therapy. Though obvious correlation between metformin and lactic acidosis in endstage renal disease was not found, caution is needed to use metformin in these patients.

\section{CONFLICT OF INTEREST}

No potential conflict of interest relevant to this article was reported.

\section{REFERENCES}

1. Fisher J, Ganellin CR. Analogue-based drug discovery II. Weinheim: John Wiley \& Sons; 2010. p. 47-9.

2. Maruthur NM, Tseng E, Hutfless S, Wilson LM, Suarez-Cuervo $\mathrm{C}$, Berger Z, et al. Diabetes medications as monotherapy or metformin-based combination therapy for type 2 diabetes: a systematic review and meta-analysis. Ann Intern Med 2016;164:740-51.

3. Misbin RI, Green L, Stadel BV, Gueriguian JL, Gubbi A, Fleming GA. Lactic acidosis in patients with diabetes treated with metformin. N Engl J Med 1998;338:265-6.

4. Stang M, Wysowski DK, Butler-Jones D. Incidence of lactic acidosis in metformin users. Diabetes Care 1999;22:925-7.

5. Salpeter SR, Greyber E, Pasternak GA, Salpeter EE. Risk of fatal and nonfatal lactic acidosis with metformin use in type 2 diabetes mellitus. Cochrane Database Syst Rev 2010;2010(4):CD002967.

6. American Diabetes Association. 9. Microvascular complications and foot care. Diabetes Care 2016;39(Suppl 1):S72-80.

7. Tuttle KR, Bakris GL, Bilous RW, Chiang JL, de Boer IH, Goldstein-Fuchs J, et al. Diabetic kidney disease: a report from an ADA Consensus Conference. Diabetes Care 2014;37:2864-83.

8. Zhou G, Myers R, Li Y, Chen Y, Shen X, Fenyk-Melody J, et al. Role of AMP-activated protein kinase in mechanism of metformin action. J Clin Invest 2001;108:1167-74.

9. Kirpichnikov D, McFarlane SI, Sowers JR. Metformin: an update. Ann Intern Med 2002;137:25-33.

10. Wang DS, Kusuhara H, Kato Y, Jonker JW, Schinkel AH, Sugiyama Y. Involvement of organic cation transporter 1 in the lactic acidosis caused by metformin. Mol Pharmacol 2003;63:844-8.

11. DeFronzo R, Fleming GA, Chen K, Bicsak TA. Metformin-associated lactic acidosis: current perspectives on causes and risk. Metabolism 2016;65:20-9.

12. Dixon SR, McKean WI, Pryor JE, Irvine RO. Changes in acidbase balance during peritoneal dialysis with fluid containing lactate ions. Clin Sci 1970;39:51-60.

13. Ilabaca-Avendaño MB, Yarza-Solorzáno G, RodriguezValenzuela J, Arcinas-Fausto G, Ramírez-Hernandez V, Hernández-Hernández DA, et al. Automated peritoneal dialysis as a lifesaving therapy in an emergency room: report of four cases. Kidney Int Suppl 2008;(108):S173-6.

14. Vaziri ND, Ness R, Wellikson L, Barton C, Greep N. Bicarbonate-buffered peritoneal dialysis. An effective adjunct in the treatment of lactic acidosis. Am J Med 1979;67:392-6.

15. Sheppard JM, Lawrence JR, Oon RC, Thomas DW, Row PG, Wise PH. Lactic acidosis: recovery associated with use of peritoneal dialysis. Aust N Z J Med 1972;2:389-92.

16. Lim PS, Huang CC, Wei JS. Metformin-induced lactic acidosis: report of a case. J Formos Med Assoc 1992;91:374-6.

17. Khan IH, Catto GR, MacLeod AM. Severe lactic acidosis in patient receiving continuous ambulatory peritoneal dialysis. BMJ 1993;307:1056-7.

18. Schmidt R, Horn E, Richards J, Stamatakis M. Survival after metformin-associated lactic acidosis in peritoneal dialysis--dependent renal failure. Am J Med 1997;102:486-8.

19. Almaleki N, Ashraf M, Hussein MM, Mohiuddin SA. Metformin-associated lactic acidosis in a peritoneal dialysis patient. Saudi J Kidney Dis Transpl 2015;26:325-8.

20. Teale KF, Devine A, Stewart H, Harper NJ. The management of metformin overdose. Anaesthesia 1998;53:698-701. 